\title{
Severe cutaneous drug reactions in Guinean children: a monocentric retrospective study of 35 cases
}

\section{Thierno Mamadou Tounkara', Houleymatou Baldé1, Mohamed Maciré Soumah', M'mah Bangoura², Boh Fanta Diané ${ }^{1}$, Moussa Keita', Mamadou Djouldé Kanté', Fodé Amara Traoré ${ }^{3}$, Fodé Bangaly Sako ${ }^{3}$, Mariam Touré ${ }^{1}$, Alhussein Doumbouya ${ }^{1}$, Mohamed Cisse ${ }^{1}$}

\begin{abstract}
${ }^{1}$ Department of Dermatology and Venerology, Teaching Hospital of Conakry and Gamal Abdel Nasser University, Conakry, Republic of Guinea, ${ }^{2}$ Department of Pediatric, Teaching Hospital of Conakry and Gamal Abdel Nasser University, Conakry, Republic of Guinea, ${ }^{3}$ Department of Infectious and Tropical Diseases, Teaching Hospital of Conakry and Gamal Abdel Nasser University, Conakry, Republic of Guinea
\end{abstract}

Corresponding author: Dr. Thierno Mamadou Tounkara, E-mail: tounkm@gmail.com

\begin{abstract}
Background: Data on Severe cutaneous drug reactions (CADRs) are not common among in sub-Saharan Africa children. The purpose of this study was to document the clinical, etiological and evolutionary aspects of Severe CDRs in children hospitalized at the dermatology department of university hospitals of Conakry. Material and Methods: Retrospective study, conducted from 1 January 2000 to 31 December 2014. Were included all children aged 0-17 years hospitalized for severe CARDs. The data collected were Socio-demographic, clinical, para-clinical and evolution variables. The data was entered and analyzed using the Excel 8.0 software. Results: During a study period, 4437 patients of all ages was hospitalized in dermatology department. 35 patients were included with an average age of 11.3 years and a sex ratio of 1.5.The main clinical patterns were: Stevens Johnson syndrome 37.14\% (13/35) Lyell syndrome $25.71 \%$ and generalized bullous fixed eruption $22.85 \%$. The drug was identified as 32 patients (91.42\%): Sulfadoxine-Pyriméthamine 40.62\%, cotrimoxazole 21.85\%, nevirapin $12.5 \%$, ampicillin 6.25\%, traditional Pharmacopoeia 6.25\% and griseofulin $3.12 \%$. It was taken following self-medication in 14 patients, including a parental initiative in 9 patients. 7 patients had a history of drug allergy and 4 were HIV positive. We recorded 5 deaths. Conclusion: Our study confirms the rarity of severe CADRs in children. The importance of the sulfadoxine-pyrimethamine in the occurrence of severe CADRs in children is the particularity of our series.
\end{abstract}

Key words : Severe cutaneous drug reaction; Children; Toxic epidermal necrolysis;

Sulfadoxine pyrimethamine; Guinea

\section{INTRODUCTION}

Cutaneous adverse drug reactions (CADRs) are mucocutaneous complications secondary to enteral, intravenous, subcutaneous or intramuscular administration of drugs [1].

They are the cause of hospitalization in dermatology services for about $1.5 \%$ of patients in France [2], $4.11 \%$ in Tunisia [3], 27\% in Togo [4], 10.40\% patients in Guinea [5] and have a high degree of semiological variability.
Two per cent of these can be severe, with severe sequelae or life threatening [6].

These severe forms include the bullous cutaneous adverse drug reactions of Stevens-Johnson syndrome (SJS) and toxic epidermal necrolysis (TEN or Lyell's syndrome), drug reaction with eosinophilia and systemic symptoms (DRESS), and acute exanthematous pustulosis (AGEP) [7].

They can occur in all individuals without distinction of age; however, they are less frequent in children with

\footnotetext{
How to cite this article: Tounkara TM, Baldé H, Soumah MM, Bangoura M, Diané BF, Keita M, Kanté MD, Traoré FA, Sako FB, Touré M, Doumbouya A Cisse M. Severe cutaneous drug reactions in Guinean children: a monocentric retrospective study of 35 cases. Our Dermatol Online. 2018;9(2):118-122. Submission: 19.09.2017; Acceptance: 02.11.2017

DOI: 10.7241 /ourd.20182.3
}

(c) Our Dermatol Online 2.2018 
an incidence of $0.9 \%$ in the Thiesen et al series in England [8].

Data on severe CADRs are not common among in sub-Saharan Africa children.

To our knowledge, no data on this subject are available in specialized hospitals in Guinea. This study was intended to document the clinical, etiological and evolutionary aspects of CADRs in children in hospitals specializing in dermatology.

\section{MATERIAL AND METHODS}

This monocentric, retrospective study was conducted during the period of January 2000 to December 31, 2014 in the Dermatology and Venereology Department of the teaching hospital of Conakry (Guinea). It is the only hospital dermatology service for a country of 11663627 million habitants. Were included all children aged 0-17 years hospitalized for severe cutaneous drug reaction during the study period.

We have considered as severe CADRs all the CADRs that lead to hospitalization or prolongation of hospitalization, life threatening, death, inability or invalidity, or other serious medical condition [9].

Were retained the Stevens-Johnson syndrome (SJS) and Lyell syndrome, DRESS (drug reaction with eosinophilia and systemic symptoms), acute generalized acute exanthematous pustulosis (AGEP) and generalized bullous fixed pigmented erythema.

The diagnosis of SJS and Lyell syndrome was selected based on the percentage of body surface peel-off: SJS $<10 \%$, overlap syndrome $10-30 \%$, and Lyell syndrome $>30 \%$ [7]. Cases of erythema multiforme and incomplete files were not included.

The data, collected from the subjects were age, sex, antecedents of allergy, name and number of the suspect drug (s), the circumstances of taking the drug (s), the time between taking the drug and the occurrence of dermatological lesions, the clinical type of cutaneous drug reaction, the evolution of the CADRs. When possible, additional tests (HIV serum, blood count, blood ionogram, liver function) were performed.

In order to establish a possible causal link, the French method was used. It is based on semio- logical and chronological arguments [10]. Due to insufficient technical platform, any allergological exploration has been carried out.

The present study was approved by the ethics committee of the medical faculty of Gamal Abdel Nasser University.

The data was entered and analyzed using the Excel 8.0 software.

\section{RESULTS}

After applying the exclusion criteria, a total of 35 patients aged 17 and under who had severe CADRs were enrolled the study. During the same period, a total of 4437 of patients of all ages was hospitalized, ie a hospital prevalence of severe CARDs in children of $0.78 \%$. Of the 35 patients, 18 were male and 17 were female. The sex ratio was 1.5 . The mean age was 11.3 years and extremes of 4,6 years and 17 years.

Nineteen $(54.1 \%)$ patients were adolescents with an age range of $13-17$ years, 9 patients $(26.1 \%)$ were great children aged between 7 and 12 years and 7 patients $(19.8 \%)$ were of young children with an age of less than 7 years. The most frequently detected children severe cutaneous drug reactions were Stevens Johnson syndrome (37.14\%), Lyell syndrome (25.71\%) (Fig. 1) and generalized bullous fixed eruption (22.85\%) (Table 1).

The interview revealed the circumstances of drug intake in all patients. This was the result of a medical prescription in 21 patients $(60 \%)$ and self-medication in 14 patients (40\%), including a parental initiative in 9 patients. In 7 out of 35 patients, there was a history of drug allergy.

Sulfadoxine-Pyrimethamine and cotrimoxazole were the most frequently involved drugs with respective

Table 1: Type and frequency of severe cutaneous drug reactions in children

\begin{tabular}{lcc}
\hline Type of severe CDRs (N=35) & Effective & Frequency (\%) \\
\hline Toxic epidermal necrolysis: & & \\
- Steven-Johnson Syndrome & 13 & 37.14 \\
$\quad$ - Lyell Syndrome & 9 & 25.71 \\
$\quad$ - Overlap SJS-Lyell & 2 & 5.71 \\
Bullous fixed pigmented erythema & 8 & 22.85 \\
Acute generalized exanthematous & 1 & 2.85 \\
Pustulosis & & \\
Dress & 1 & 2.85 \\
CDRs not specified & 1 & 2.85 \\
Total & 35 & 100 \\
\hline
\end{tabular}


proportions of $40.62 \%$ (13/32), cotrimoxazole $21.85 \%$ (7/32). The clinical types of severe CADRs identified and the main drugs involved are detailed in Table 2.

The lesions appeared between one and three weeks in 19 patients, in less than one week in 8 patients. The time to onset was not specified in 8 patients. HIV serology was performed in 21 patients $(60 \%)$. It was positive for HIV 1 in 4 patients, ie 19\%.

We recorded 5 deaths (14.2\%), all of which occurred in patients with Lyell's syndrome (55.5\%), of which 3 were infected with HIV. Two cases of symblepharon sequelae following Lyell syndrome were noted.

\section{DISCUSSION}

This study describes the clinical, etiological and evolutionary profile of severe cutaneous drug reactions in children based on the information contained in the medical records of patients hospitalized in the Department of Dermatology at the University Hospital

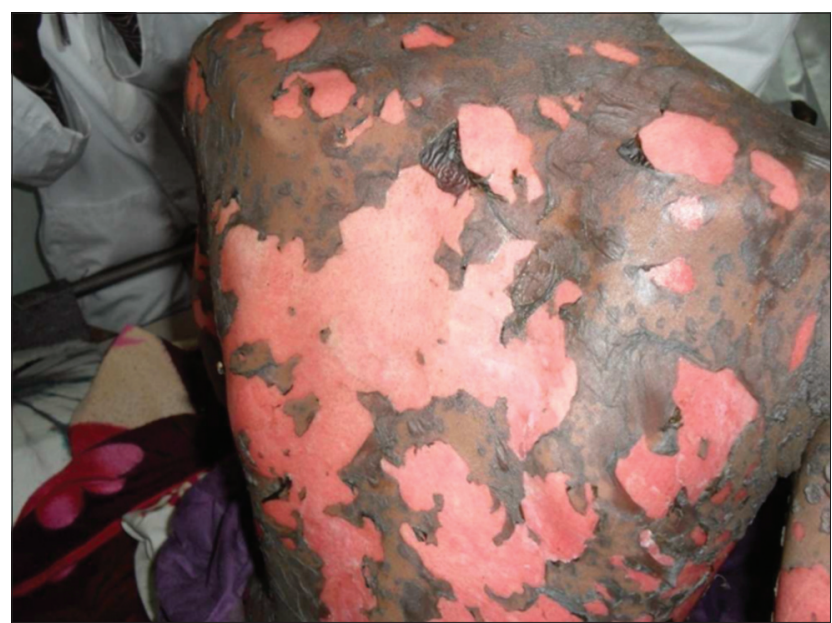

Figure 1: Lyell syndrome with dermal exposure in a 16-year-old patient. of Conakry from 01 January 2000 to 31 December 2014. Although the service of dermatology is the only service of this type in Guinea, our data are not exhaustive.

It is possible that some children suffering from severe CADRs may outside hospital structures due to accessibility problems, both economic and geographical. To these are added cultural contingencies which make the patients first practice self-medication and thus rarely resort to a first-line medical consultation consulting first the traditional practitioners. However, with 35 cases of severe CDRS in children collected in 14 years, ie a hospital prevalence of $0.78 \%$ and a mortality of $14.2 \%$, our results are similar to those of the literature on the severity of severe childhood CADRs and mortality severe forms of Stevens Johnson syndrome and Lyell Syndrome. These two CADRs were respectively $1^{\text {st }}$ and $2^{\text {nd }}$ severe CADRs in hospitalization in children. These two entities are the spectrum of one disease, differing only by their extent of skin detachment: SJS $<10 \%$, overlap syndrome 10 to $30 \%$, and Lyell syndrome > 30\% [7]. DRESS and AGEP were less represented with 1 case each. The weakness of the diagnostic facilities and the low frequentation of the hospital structures can explain this low representation.

For Roujeau J C, the prognosis of SSJ and Lyell syndrome in children is much better compared to the adult with a mortality of the order of $5 \%$ for all cases where the epidermal detachments exceed $10 \%$ of the body surface [11].

Our results suggest that in both children and adults in Africa, the mortality of severe CADRs remains particularly high, linked in part to insufficient technical platform and HIV infection, as already noted by other authors $[5,12]$.

Table 2: Distribution of severe cutaneous drug reactions in children according to the drug in cause

\begin{tabular}{|c|c|c|c|c|c|c|c|}
\hline \multirow{2}{*}{$\begin{array}{l}\text { Type of severe CDRs } \\
\text { Drug in cause }\end{array}$} & \multicolumn{3}{|c|}{ Toxic epidermal necrolysis } & \multirow{2}{*}{$\begin{array}{l}\text { Bullous fixed } \\
\text { pigmented } \\
\text { erythema }\end{array}$} & \multirow[t]{2}{*}{ AGEP } & \multirow[t]{2}{*}{ DRESS } & \multirow{2}{*}{$\begin{array}{c}\text { CDRs } \\
\text { not } \\
\text { specified }\end{array}$} \\
\hline & $\begin{array}{c}\text { Steven-Johnson } \\
\text { syndrome }\end{array}$ & Lyell syndrome & $\begin{array}{l}\text { Overlap } \\
\text { SJS-Lyell }\end{array}$ & & & & \\
\hline Sulfadoxine -Pyriméthamine $n=13$ & 7 & 3 & 1 & 2 & & & \\
\hline Salts of Quinine $n=1$ & & 1 & & & & & \\
\hline Cotrimoxazole $n=7$ & 2 & 2 & & 3 & & & \\
\hline Ampicillin $n=2$ & 1 & & & & 1 & & \\
\hline Aspirin $n=2$ & & & & 2 & & & \\
\hline Nevirapin $n=4$ & 3 & 1 & & & & & \\
\hline Greseofulin $n=1$ & & & & & & & 1 \\
\hline Traditional Pharmacopoeia $n=2$ & & & 1 & & & 1 & \\
\hline Medication found $n=3$ & & 2 & & 1 & & & \\
\hline Total & 13 & 9 & 2 & 8 & 1 & 1 & 1 \\
\hline
\end{tabular}


The comparison of the frequencies of the different types of severe CADRs encountered during our study in other countries is difficult because studies differ method of recruiting patients. Our study focused exclusively on the hospital. The forms of CADRs called benign as the fixed drug eruption or maculo-papular exanthema require hospitalization only when signs of gravity cause it. The forms of fixed drug erythema hospitalized in our series was generalized. Such a clinical forms will indicate a reintroduction of the inducing drug.

The proportion of the various drugs responsible for CADRs depends on the epidemiology of infantile diseases in the environment, the practice of physician and the use of these drugs in the general population, all of which are related to time [13].

The responsibility of sulfonamides anti-infectious such as cotrimoxazole in the occurrence of severe CADRs, as found in the present study, is a classic fact already reported by other authors $[14,15]$.

However, in our study, as in that of Sarah et al. [16] in Côte d'Ivoire, the combination of sulfadoxinepyrimethamine was the first drug to induce severe cutaneous drug reactions in children in Conakry.

Unlike the French and Tunisian studies where this first place is occupied respectively by vaccines and penicillin. The application of the accountability criteria has made it possible to standardize etiological research and to compare our results with those of other authors (Table 3). Antiretrovirals, in this case nevirapine, are the third most important drug responsible for severe CADRs in our study. This third place is occupied by psycho stimulants in France and anticonvulsants in India and Malaysia.
The important role of the sulfadoxine-pyrimethamine combination in the occurrence of children CADRs is the particularity of our series. In malaria-endemic areas such as Guinea, sulfadoxine-pyrimethamine is recommended for the prevention of malaria in combination with amodiaquine during the high malaria season to prevent disease, with the objective of maintaining concentrations treatment of antimalarial drug in the blood during the period when the risk of contracting malaria is higher [22].

The use of this molecule in monotherapy and often in self-medication as observed in $40 \%$ of our patients is an inappropriate practice. Indeed, for Laroche et al, selfmedication and the illicit sale of medicines increases the inappropriate consumption of medicines favoring the occurrence of potentially preventable side effects [23].

Two percent of the patients in our series had a history of drug allergy. One might think that a prescription made under the conditions of a medical consultation taking into account the history would have avoided the occurrence of the cutaneous drug eruption $2 \%$ of the patients. In addition to the risk of occurrence of severe toxidermia at the occasional fatal outcome, the use of the sulfadoxine-pyrimethamine combination as monotherapy favors the emergence of resistance mutations of Plasmodium falciparum. This resistance makes the fight against malaria even more difficult in endemic areas [24].

Efforts in the fight against the illicit sale of medicines, coupled with public awareness and education campaigns on the harmful effects of self-medication, may contribute to reducing the prevalence of these severe cutaneous drug reactions in children.

Table 3: Main drugs involved in descending order in different series of cutaneous adverse drug reactions (CADRs) in Children

\begin{tabular}{|c|c|c|c|}
\hline Rank & $1^{\text {st }}$ Rank & $2^{\text {nd }}$ Rank & $3^{\text {rd }}$ Rank \\
\hline our serie (Guinée) & $\begin{array}{l}\text { Antimalarial } \\
\text { (Sulfadoxine-Pyriméthamine) }\end{array}$ & $\begin{array}{l}\text { Sulfonamides } \\
\text { (Cotrimoxazole) }\end{array}$ & $\begin{array}{l}\text { Antirétroviraux } \\
\text { (Névirapine) }\end{array}$ \\
\hline Adegbidi et al Benin [13] & $\begin{array}{l}\text { Sulfonamides } \\
\text { (Cotrimoxazole) }\end{array}$ & $\begin{array}{l}\text {-Penicillin } \\
\text {-Vaccine } \\
\text {-Acetaminophen }\end{array}$ & $\begin{array}{l}\text { non-steroidal anti-inflammatory drug } \\
\text { (Aspirin) }\end{array}$ \\
\hline Khaled A et al Tunisie [17] & Penicillin & $\begin{array}{l}\text { Non-steroidal anti-inflammatory } \\
\text { drug (Aspirin) }\end{array}$ & $\begin{array}{l}\text { Antiepileptics } \\
\text { (Phenobarbital) }\end{array}$ \\
\hline Dilek et al Turkey [18] & Penicillin and its derivatives & Acetaminophen & Vitamins and minerals \\
\hline Damien et al Saint-E'tienne [19] & $\begin{array}{l}\text { Vaccin BCG (bacille de Calmette } \\
\text { et Guerin) }\end{array}$ & $\begin{array}{l}\text { Anti-neoplastic and } \\
\text { immunomodulating } \\
\text { agents(Asparaginase) }\end{array}$ & $\begin{array}{l}\text { Psychostimulant } \\
\text { (Méthylphénidateà }\end{array}$ \\
\hline Rosli R et al Malaysia [20] & $\begin{array}{l}\beta \text {-Lactam Antibacterials, } \\
\text { Penicillins }\end{array}$ & Analgesics and Antipyretics & Antiepileptics \\
\hline Qayoom et al Inde [21] & Antimicrobials(ofloxacin) & $\begin{array}{l}\text { Non-steroidal anti-inflammatory } \\
\text { drugs( Piroxicam) }\end{array}$ & $\begin{array}{l}\text { Antiepileptics } \\
\text { ( Phenytoin) }\end{array}$ \\
\hline
\end{tabular}


In three patients, the inducer drug was not found, which increases the risk of accidental reintroduction of the drug.

\section{CONCLUSION}

Severe cutaneous drug reactions are relatively rare in specialized hospitals in Conakry. As in adults, severe and $\mathrm{HIV}$-associated forms have a poor prognosis. The etiological profile of the 35 cases of severe CADRs observed in the children of our serie is generally comparable to those already reported in the literature. However, the importance of the sulfadoxinepyrimethamine combination in the occurrence of severe CADRs in children is the particularity of our series.

\section{REFERENCES}

1. Barbaud A. Prise en charge globale des toxidermies. Ann Dermatol Venereol. 2007;134:391-401.

2. Modeste AB, Josset V, Hautemaniere A, Roujeau JC, Plantin P, Joly P, et al. Enquête sur l'activité des services de dermatologie hospitaliers français. Ann Dermatol Venereol. 2002;11:1266-70.

3. Chaabane H, Masmoudi A, Amouri M, Ghorbel S, Boudaya S, Hammami S, et al. Profil des toxidermies médicamenteuses : étude prospective de 118 cas. Tunis Med. 2013;91:514-20.

4. Mouhari-Toure A, Klu AS, Kombaté K, Saka B, Tchangai-Walla $\mathrm{K}$, Pitche P. [Presenting disorders and characteristics of inpatients at a dermatology unit in Lomé, Togo]. Ann Dermatol Venereol. 2009;5:448-9.

5. Cissé M, Tounkara TM, Diané BF, Soumah MM, Keita M, Sako FB, et al . Severe Drug Eruption in Guinea Conakry. J Cosm Dermatol Scien Applicat. 2014;4:339-43.

6. Wolf R, Orion E, Marcos B, Matz H. Life-threatening acute adverse cutaneous drug reactions. Clin Dermatol. 2005;23:171-81.

7. Lebrun-Vignes B, Valeyrie-Allanore L. Cutaneous adverse drug reactions. Rev Méd Int. 2015;36:256-70.

8. Thiesen S, Conroy EJ, Bellis JR, Bracken LE, Mannix HL, Bird KA, et al. Incidence, characteristics and risk factors of adverse drug reactions in hospitalized children - a prospective observational cohort study of 6,601 admissions. BMC Med. 2013;11:237.

9. Efficacy guidelines: ICH [Internet]; cited 2017 august 29 Available from http://www.ich.org/products/guidelines/efficacy/article/ efficacy-guidelines.html.

10. Begaud B, Evreux JC, Jouglard J, Lagier G. Imputation of the unexpected or toxic effects of drugs. Actualization of the method used in France. Therapie. 1985;40:111-8.
11. Roujeau JC. Toxidermies de l'enfant. Arch Pédiatr. 2000;7:215-7.

12. Mame Thierno D, On S, Thierno Ndiaye S, Ndiaye B. [Lyell syndrome in Senegal: responsibility of thiacetazone]. [Article in French] Ann Dermatol Venereol. 2001;128:1305-7.

13. Adegbidi H, Atadokpede F, Sagbo G, Koudoukpo C, D'Almeida M, Teclessou J, et al. Toxidermie chez les enfants à cotonou, Benin. Mali Méd. 2012;27:42-6.

14. Sharma VK, Dhar S. Clinical pattern of cutaneous drug eruption among children and adolescents in north India. Pediatr Dermatol. 1995; $12: 178-83$

15. Levi N, Bastuji-Garin S, Mockenhaupt M, Roujeau JC, Flahault A, Kelly JP, et al. Medications as risk factors of Stevens Johnson syndrome and toxic epidermal necrolysis in children: a pooled analysis. Pediatrics 2009;123:e297-e304.

16. Kourouma HS, Kouassi YI, Diabaté A, Sangaré A, Ecra EJ, Kaloga M, et al.[Clinical epidemiological profile of severe cutaneous drug reactions in children in Abidjan (Côte d'Ivoire)]. Bull Soc Pathol Exot. 2014;107:142-5.

17. Khaled A, Kharfi M, Ben Hamida M, El Fekih N, El Aidli S, Zeglaoui $\mathrm{F}$, et al. Cutaneous adverse drug reactions in children. A series of 90 cases. Tunis Med. 2012;90:45-50.

18. Dilek N, Özkol HU, Akbaş A, Kılınç F, Dilek AR, Saral Y, et al. Cutaneous drug reactions in children: a multicentric study. Postepy Dermatol Alergol. 2014;31:368-71.

19. Damien S, Patural H, Trombert-Paviot B, Beyens MN. [Adverse drug reactions in children: 10 years of pharmacovigilance]. Arch Pediatr. 2016;23:468-76.

20. Rosli R, Dali AF, Aziz NA, Ming LC, Manan MM. Reported Adverse Drug Reactions in Infants: A Nationwide Analysis in Malaysia. Front Pharmacol. 2017;10:30.

21. Qayoom S, Bisati S, Manzoor S, Sameem F, Khan K. Adverse cutaneous drug reactions--a clinico-demographic study in a tertiary care teachinghospital of the Kashmir Valley, India. Arch Iran Med. 2015;18:228-33.

22. Chimioprevention du paludisme saisonnier par Administration de Sulfadoxine pyriméthamine et d'amodiaquine aux Enfants. cited 2017 august 29 Available from: https://www.mmv.org/sites/ default/files/uploads/.../OMS_Guide_de_terrain.pdf

23. Laroche ML, Charmes JP, Nouaille Y, Picard N, Merle L. Is inappropriate medication use a major cause of adverse drug reactions in the elderly? Br J Clin Pharmacol. 2007;63:177-86.

24. Berzosa P, Esteban-Cantos A, García L, González V, Navarro M, Fernández T, et al. Profile of molecular mutations in pfdhfr, pfdhps, pfmdr1, and pfcrt genes of Plasmodium falciparum related to resistance to different anti-malarial drugs in the Bata District (Equatorial Guinea). Malar J. 2017;16:28.

Copyright by Thierno Mamadou Tounkara, et al. This is an open access article distributed under the terms of the Creative Commons Attribution License, which permits unrestricted use, distribution, and reproduction in any medium, provided the original author and source are credited. Source of Support: Nil, Conflict of Interest: None declared. 